\title{
Libro álbum y formación básica docente. Un estudio de caso en la Universidad del Quindío
}

\author{
Mariana Valencia Leguizamón \\ Universidad del Quindio
}

Neus Real

Universitat Autònoma de Barcelona

(Texto recibido el 2 de junio de 2019; aceptado el 15 de julio de 2019; versión final el 24 de julio de 2019)

DOI: https://doi.org/10.5565/rev/jt13.847

Resum: L'article presenta una investigació amb estudiants de magisteri de la Universitat del Quindío (Colòmbia) per contrastar els seus sabers i estratègies lectores davant d'un àlbum il·lustrat abans i després d'un curs sobre aquesta mena de llibres. Les dades, recollides mitjançant dos comentaris d'Un dia diferente para el señor Amos, s'analitzen a partir de categories que corresponen als aspectes literaris característics dels àlbums amb presència rellevant en l'obra de Philip C. Stead i Erin E. Stead. Els resultats mostren que una formació bàsica docent focalitzada en els coneixements i les habilitats que reclama la lectura d'àlbums reverteix en un increment significatiu de la competència literària dels futurs mestres, per bé que caldria aprofundir especialment en la lectura d'imatges, el llibre com a objecte i les seves convencions i possibles subversions.

Paraules clau: formació bàsica docent; literatura infantil i juvenil; llibre àlbum; educació literària; didàctica de la literatura

\begin{abstract}
This article presents a research carried out with schoolteaching students of the University of Quindío (Colombia) to contrast their knowledge and reading strategies when facing a picturebook before and after receiving training on this kind of books. Collected through two commentaries of A Sick Day for Amos McGee, data were analysed by means of categories corresponding to picturebooks characteristic literary aspects with a relevant presence in Philip C. Stead and Erin E. Stead's picturebook. The results show that an initial teacher education focused on knowledge and skills demanded by picturebook reading provokes an increase of future teachers literary competence, although image reading, the book as an object and its conventions and possible subversions should be deepened on.
\end{abstract}

Keywords: initial teacher education; children's literature; picturebooks; literary education; didactics of literature 
Resumen: El artículo presenta una investigación con estudiantes de magisterio de la Universidad del Quindío (Colombia) para contrastar sus saberes y estrategias lectoras frente a un álbum ilustrado antes y después de un curso sobre este tipo de libros. Los datos, recogidos mediante dos comentarios de Un día diferente para el señor Amos, se analizan a partir de categorías que corresponden a los aspectos literarios característicos de los libros álbum con presencia relevante en la obra de Philip C. Stead y Erin E. Stead. Los resultados muestran que una formación básica docente focalizada en los conocimientos y las habilidades que reclama la lectura de álbumes revierte en un incremento significativo de la competencia literaria de los futuros maestros, si bien habría que profundizar especialmente en la lectura de imágenes, el libro como objeto y sus convenciones y posibles subversiones.

Palabras clave: formación básica docente; literatura infantil y juvenil; libro álbum; educación literaria; didáctica de la literatura

\section{Introducción}

La Didáctica de la lengua y la literatura (DLL), campo científico que opera sobre la interacción dinámica entre docente, alumno y objeto de enseñanza-aprendizaje, considera los referentes enmarcados en las particularidades del contexto que se ocupan de cada uno de estos componentes y los vincula con la investigación en la propia disciplina. Esta perspectiva es determinante porque acentúa el interés de la DLL en las relaciones concretas y cambiantes que se establecen dentro del sistema didáctico, que trasciende la relación enseñante/enseñado (Chevallard, 1991). En el ámbito específico de la didáctica de la literatura, se ha demostrado que el estudio de la relación entre los libros infantiles y la formación docente abre vías de mejora del trabajo en las aulas (Cerrillo, 2016; Díaz Armas, 2008; Munita, 2018; Palomares, 2015; Silva-Díaz, 2001a, 2001b). El presente artículo se sitúa en esta línea investigativa al enfocarse en una formación docente que permita responder adecuadamente a las particularidades del libro álbum y, por tanto, explotarlo didácticamente en la educación literaria de los alumnos de primaria. Con este propósito, reportamos el contraste entre los saberes y estrategias lectoras de un grupo de futuros maestros colombianos en relación con Un día diferente para el señor Amos, de Philip C. Stead y Erin E. Stead, antes y después de cursar una asignatura focalizada en obras de este tipo ${ }^{1}$. 


\section{Educación literaria, libro álbum y formación docente}

La educación literaria es el proceso de formación de lectores potencialmente aptos para la interpretación y el goce de obras literarias, en cuyo marco se teje la interacción entre el maestro mediador, el alumno lector y las obras mismas. En la presente investigación nos centramos en los libros álbum por el valor que en ellos tiene la imagen en relación con el código verbal y por su particular adecuación para adelantar procesos de formación lectora en primaria, cuando la mediación es fundamental (Arizpe y Styles, 2004; Duran, 2009; Ruiz Domínguez, 2008; Silva-Díaz, 2006, 2005; Turrión, 2012).

La interdependencia entre el espacio del alumno lector y del maestro facilitador explica que el desarrollo de la competencia literaria gravite a lo largo del proceso de formación al tiempo que lo orienta: las programaciones del mediador se dirigen hacia su despliegue, los avances del lector la construyen y la interacción resultante hace posible su monitoreo y su mejoramiento en una misma práctica de enseñanza-aprendizaje. En consecuencia, son de conocimiento ineludible para el docente los rasgos particulares de las obras y sus facultades para la formación del lector literario (Colomer, 1991/1998), que en el libro álbum son: a) el hecho de que la imagen "no se incluya", sino que "haga parte de él" (Duran, 2007); b) las convenciones de expresión y recepción propias (Silva-Díaz, 2014) en las cuales se mezclan la alfabetización verbal y la visual, ésta anclada a la "lectura de imágenes" y sus elementos constituyentes (Bosch y Duran, 2009); c) la circunstancia de que, aunque la lectura visual es más intuitiva que la verbal, la habilidad deductiva juega un papel clave en su decodificación (Lee, 2014), y d) el lugar que ocupa el componente material del libro en la articulación de sentido (Van der Linden, 2015). El mediador, pues, debe poder reconocer los componentes de los álbumes e identificar sus posibilidades para objetivos específicos de educación literaria (Belmiro, 2010; Silva-Díaz, 2001a, 2001b). A estos vectores que impactan la mediación -los rasgos distintivos del libro álbum y los modos de lectura que promueven- se añadiría el trabajo sobre las habilidades lectoras relativas a las temáticas, que en la actualidad supone un reto por la concepción de lo que "debiera ser" un libro para niños (Munita, 2018), lo que exige el tratamiento didáctico apropiado de unas obras que implican diferentes formas de comprensión y temas complejos. Para ahondar en la intersección entre libro álbum y formación docente, abordemos primero cada uno de ellos. 
En el concepto de libro álbum convergen tres componentes clave: visual, verbal y material (Silva-Díaz, 2014; Silva-Díaz y Corchete, 2002). El “objeto libro” no funciona sólo como contenedor, sino que es "el objeto físico en su conjunto, desde la portada hasta la contraportada, incluyendo cada pasada de página" (Doonan, 2005, p.47). Esta condición hace que los álbumes detonen diferentes lecturas relacionadas con las imágenes, las palabras y la materialidad. Todo ello, en sintonía con las diferentes voces que resuenen en la mente del lector en su encuentro con la obra (Mendoza, 1998). La coexistencia de estos tres componentes no obliga, empero, su participación equitativa en la construcción semiótica. En cuanto a los códigos verbal y visual, la imagen se asume como primordial (Bosch, 2007), aun cuando se reconoce que las palabras aportan de manera sustancial al sentido incluso en el caso de los libros álbum silentes (Hanan, 2017), en los que el título es siempre relevante. En contraste, el significado del componente material tiende a ser un recurso menos frecuente ${ }^{2}$. Más allá de cuánto se exploten y de las maneras como interactúen, para una interpretación completa resulta clave la conciencia de las posibilidades de sentido de los tres componentes. Destaca así el papel del facilitador entre los niños y los álbumes, sean sencillos -pero con imágenes y palabras articuladas dialógicamente, gracias a las cuales el pequeño, "con la mediación de un lector adulto, descubrirá la relación entre el lenguaje visual y el verbal” (Lioni, 2005, p. 153) - o complejos, caso en que la mediación deberá canalizar el acercamiento a temas trascendentes y estructuras sofisticadas -por ejemplo en los álbumes metaficcionales, que subvierten las convenciones literarias (Silva-Díaz, 2005).

Por su parte, la formación básica docente determina la educación literaria en los centros escolares, que promueven concepciones lectoras, movilizan corpus y validan prácticas. Estas prácticas, aunque definidas por su valor “preparatorio" inicial, condicionan el repertorio didáctico del maestro de literatura. Dadas las carencias que a menudo caracterizan su preparación, se ha insistido en la necesidad de fortalecer este campo-etapa inicial (Díaz Armas, 2008; Dueñas et al., 2013; Munita, 2018). Tal formación, calificada como deficiente por los mismos estudiantes de magisterio (Palomares Marín, 2015), sufre de una falta de enseñanza sistemática sobre la literatura infantil y juvenil (LIJ) contemporánea y de las limitaciones de su tratamiento estrictamente funcional. Los programas formativos deberían incluir conocimientos específicos sobre la LIJ (Silva-Díaz, 2001a), la interacción entre lenguajes simbólicos (Belmiro, 2010) y los saberes y prácticas didácticas necesarios 
para la adecuada formación escolar de lectores literarios (Fittipaldi, 2013; Fittipaldi y Colomer, 2014). Hacerlo da resultados evidentes (Real y Gil, 2018).

Hay que decir, sin embargo, que una dificultad importante es el desconcierto que la complejidad de los álbumes despierta en los futuros maestros, que suelen estimar que estas obras resultan inapropiadas para los niños (Mercier y Tourron-Bertrand, 2013). Contra tal deficiencia, resalta el valor de adelantar procesos de lectura para que los docentes en formación pierdan el temor al libro álbum y reconozcan su potencial a la vez que afianzan y consolidan los propios procesos de lectura (Massengill, Dvorak y Bates, 2007; Warmack, 2007). Se trata de sensibilizar al profesorado, transformar sus creencias y ayudarle a explorar didácticamente un producto esencial de la LIJ actual. La apertura de espacios de discusión sobre los álbumes (elementos estéticos, efectos sobre el lector adulto y posibles abordajes en el aula) contribuye a generar actitudes favorables, ya que "el cambio en la visión que se tiene de la LIJ sucede, en buena medida, por el descubrimiento de una literatura que también puede ser disfrutada y leída con placer por el adulto" (Munita, 2018, p.117). La naturaleza del álbum, no obstante, conlleva reconocer las múltiples dimensiones implicadas en su construcción de sentido, para cuyo dominio se precisa de pautas específicas que han de constituir objetos de enseñanza y de aprendizaje obligatorios. El mediador debería familiarizarse con las convenciones temáticas, formales y artísticas de los álbumes, ya que este es el requisito indispensable para su posterior explotación escolar. Tal premisa fundamentó, precisamente, la investigación que se detalla a continuación.

\section{Metodología y contextualización de la investigación}

Este trabajo constituye un estudio de caso y atiende al enfoque cualitativo de orientación hermenéutica (De Souza Minayo, 2009; Gurdián, 2007; Martínez Miguélez, 2010). Su objetivo general es determinar la incidencia de una formación básica docente sobre el libro álbum en los saberes y habilidades interpretativas del futuro profesorado. La muestra del estudio está constituida por 22 estudiantes de la Universidad del Quindío: 8 hombres y 14 mujeres de entre 18 y 37 años que en el primer semestre de 2015 se matricularon en Didáctica de la literatura infantil y juvenil de la licenciatura en Español y Literatura (actualmente, Literatura y Lengua Castellana). "Sin que necesariamente sea representativo del universo o 
población que se estudie” (Hernández, Fernández y Baptista, 2006, p.562), el grupo se integra en el colectivo de futuros maestros de educación primaria del país.

Didáctica de la literatura infantil y juvenil es un curso obligatorio perteneciente a la línea Didáctica de la lengua materna y la literatura de la malla curricular, y cuenta con 3 créditos y 4 horas presenciales durante las 16 semanas del ciclo académico semestral. La asignatura se articula en cuatro unidades centradas en: 1) visibilizar y comprender la relación entre la LIJ, la competencia literaria y la educación literaria; 2) abordar el concepto de libro álbum para mostrar las diversas maneras en que sus componentes pueden incidir en la construcción global del sentido y develar la importancia de la exploración y de la implementación de estrategias de lectura completa de las obras (Solé, 2001); 3) trabajar la narración literaria -los componentes de la historia y del discurso (Colomer, 1998; Silva-Díaz, 2005)- haciendo confluir los saberes derivados de ello con los saberes sobre el libro álbum para potenciar su interpretación en profundidad y la identificación de sus posibilidades en el desarrollo de la competencia literaria en educación primaria, y 4) aplicando los saberes y habilidades anteriormente adquiridos, partir de objetivos específicos de aprendizaje para analizar los álbumes narrativos literarios de la Colección Semilla 3 .

Con el fin de establecer los conocimientos y las estrategias lectoras de los participantes en relación con los libros álbum antes y después del curso -y saber así cuál es el alcance efectivo de esta formación-, el instrumento de recolección de datos elegido fue el comentario de texto escrito, puesto que permite desarrollar un análisis pormenorizado. Para guiar el análisis hacia una valoración que integrara los componentes material, visual y verbal del álbum sin incidir significativamente en el proceso escritural, orientamos el comentario con 9 preguntas optativas, abiertas y carentes de metalenguaje, diseñadas tomando en cuenta los elementos de la historia y del discurso narrativo y los estudios sobre educación literaria y sobre libro álbum (Bosch, 2007; Bosch y Duran, 2009; Colomer, 2005, 1999/2010; Consejo, 2011; Duran, 2000, 2007, 2008, 2009; Fittipaldi, 2013; Lluch, 2009; Silva-Díaz, 2005, 2014; Van der Linden, 2006, 2015). Un día diferente para el señor Amos fue escogido para el comentario por su calidad literaria y por unos rasgos estéticos distintivos del álbum que, aquí, implican activamente al lector: temática compleja (soledad, vejez y muerte), distancia interpretativa (humor), relación de potenciación entre código visual y verbal (en la construcción de personajes y sus relaciones), integración a la secuencia narrativa del soporte 
(cubiertas, página legal y guardas) y uso poco convencional de peritextos como el título (Colomer, 1998; Lluch, 2009; Silva-Díaz, 2014; Van der Linden, 2015)4. El instrumento se aplicó previamente y posteriormente a la realización de la asignatura.

Los resultados obtenidos se presentan divididos en cinco apartados correspondientes a las categorías de análisis, emergidas de las preguntas orientativas del comentario y de los elementos considerados por los participantes en la segunda ocasión (una combinación que ofrece el espectro pertinente para su sistematización). Presentamos primero la explicación de cada categoría, anotando los interrogantes planteados y las subcategorías en que se han dividido los datos. Seguidamente incluimos una tabla, fruto del vaciado de los comentarios, que cuantifica los saberes y habilidades de los estudiantes antes (PRE) y después (POST) de la formación con el objetivo de mostrar su incidencia general mediante el contraste de porcentajes derivados del número de respuestas. Finalmente, se consideran cualitativamente los datos con ejemplos de las respuestas de los participantes, cuyo anonimato se garantiza mediante una identificación alfabético-numérica ( $\mathrm{E}$ de estudiante más un número). $\mathrm{El}$ contraste mixto resultante permite exponer y discutir los resultados de forma sintética en una panorámica que no excluye los matices.

\section{Resultados y discusión}

Los resultados muestran una progresión muy significativa, especialmente interesante en algunos aspectos, en cuanto a los saberes y estrategias de los estudiantes relativos a: 1) el ingreso al libro y la lectura visual; 2) la lectura material y las estrategias de lectura implicadas; 3) la lectura verbal y la identificación de lugares comunes o singularidades e intertextualidad; 4) las dimensiones ético-filosófica y afectiva de la educación literaria, y 5) la construcción de la narración. Veámoslo punto por punto.

\section{Ingreso al libro y lectura visual}

Al enfrentarse a un álbum, un primer paso es el ingreso al libro y su lectura visual. Darse cuenta del tipo de obra y de la importancia que en ella tiene la imagen es fundamental para su comprensión. Las preguntas planteadas en este punto son: ¿Se refieren los participantes al libro álbum como modalidad de texto a comentar? ¿De qué manera? ¿Aluden al código 
visual? ¿En qué forma? Los aspectos más relevantes son, aquí, el tipo de obra, la alusión al doble código visual/verbal, la referencia al color (alusión a su presencia y sentido) y la remisión a las funciones de la imagen (narrativa y expresiva).

Cuadro 1. Ingreso al libro y lectura visual. Contraste cuantitativo en porcentajes

\begin{tabular}{|c|c|c|c|c|c|c|}
\hline & \multicolumn{2}{|c|}{$\begin{array}{c}\text { INGRESO } \\
\text { AL LIBRO }\end{array}$} & \multicolumn{2}{c|}{ COLOR } & \multicolumn{2}{c|}{$\begin{array}{c}\text { FUNCIONES } \\
\text { DE LA IMAGEN }\end{array}$} \\
\cline { 2 - 7 } & $\begin{array}{c}\text { Tipo } \\
\text { de obra }\end{array}$ & $\begin{array}{c}\text { Alusión al doble código } \\
\text { visual/verbal }\end{array}$ & $\begin{array}{c}\text { Alusión a su } \\
\text { presencia }\end{array}$ & Sentido & Narrativa & Expresiva \\
\hline \multirow{2}{*}{$\frac{\pi}{2}$} & $36.36 \%$ & $9.1 \%$ & $22.73 \%$ & $4.55 \%$ & $9.09 \%$ & $9.09 \%$ \\
\hline \multirow{2}{*}{} & $72.73 \%$ & $77.27 \%$ & $81.82 \%$ & $81.82 \%$ & $86.36 \%$ & $86.36 \%$ \\
\hline
\end{tabular}

En el comentario inicial sólo algunos participantes aluden explícitamente al tipo de obra, el libro álbum. La presencia de la imagen, en cambio, es reconocida de manera generalizada, pero se ignora la importancia de integrar la lectura de los códigos verbal y visual para construir el sentido de la obra. La ausencia de conciencia sobre el valor de la interpretación integrativa de ambos códigos se acentúa con la falta de herramientas para hablar de las imágenes. De ahí que no haya referencias a otros elementos visuales además del color y que en escasas oportunidades se remita a las funciones de la ilustración: no hay atención pormenorizada a sus elementos ni identificación de los significados que aportan, que en Un día diferente para el señor Amos resultan claves. La tendencia predominante es enunciar los colores -«Amos es un hombre que utiliza vestimenta verde» (E21) - y vincular la imagen con la ternura y la alegría asociada a los personajes: «Los animales manejan gestos muy tiernos entre ellos y con Amos, y esto genera un ambiente muy acogedor» (E4). No se incluyen la tristeza ni la preocupación que también expresan los rostros, lo que la postura de los cuerpos 
transmite o el humor que las imágenes introducen ocasionalmente. Esta aproximación limitada al código visual se acentúa con la vinculación reduccionista imágenes/destinatario infantil (una cuestión que retomamos en los próximos apartados).

El comentario final, en contraste, evidencia cómo reconocer la tipología de la obra induce una conciencia inmediata sobre el doble código y su relevancia significativa. La mayoría de los participantes menciona que se trata de un libro álbum y nombra a autor e ilustradora, en una explicitación del valor de ambos artistas que conecta con la admisión del papel destacado de cada componente. En consecuencia, aparecen referencias a la complementariedad narrativa texto/ilustración y precisiones sobre las diferentes informaciones que aportan, en una comprensión mucho mayor de la necesidad de ahondar en los códigos verbal y visual: «la imagen es un soporte del texto porque en la imagen aparecen elementos que las palabras no dicen» (E19). Las alusiones a la imagen se incrementan y, además de remitir al color, los participantes comentan su ausencia, el fondo de la página, el contraste, la línea y otros elementos para explicar cómo inciden en la construcción y el sentido de la historia. Por ejemplo:

Toda la obra cuenta con un fondo blanco que, a mi modo de ver, tiene la función de resaltar los personajes. [ ] Tiene una paleta de colores muy sobrios que reflejan un poquito de melancolía. Las líneas no son perfectas, con el fin de mostrar que se trata de dibujos, no como en otros libros álbum, donde los ilustradores utilizan otras técnicas para que se vean más reales. En su mayoría [las imágenes] tienen ritmo y simetría. La expresión de los animales y de Amos es tranquila y en momentos sonríen, no de manera amplia pero sí tranquila, afín con la tonalidad (E19).

Se produce, pues, un desplazamiento desde la identificación estricta de la presencia de imágenes y la mención descriptiva de sus colores hacia un análisis y una atribución de significado a sus diferentes aspectos que son fruto de la lectura extensiva e intensiva (Mendoza, 1998) de libros álbum durante el curso, del saber adquirido sobre la imagen y sus funciones narrativa y expresiva y del dominio del metalenguaje pertinente. Al ser conscientes del doble código característico del libro álbum y de su forma de operar, los estudiantes descartan cualquier referencia no interpretativa a la imagen y despliegan conocimientos y estrategias para proponer sentidos más afinados y profundos de Un día diferente para el señor Amos, como ilustra este fragmento: «El globo que acompaña toda la narración está muy relacionado con la vida del señor Amos, tal vez simboliza su vida» (E19). 


\section{Lectura material y estrategias de lectura implicadas}

En el libro álbum, como se ha dicho, el componente material es esencial, y las formas de acercarse a él tienen especial interés a la hora de determinar procesos de verificación, autocontrol y relectura (Fittipaldi, 2013). Se plantean, en este punto, estos interrogantes: ¿Los participantes tienen consciencia de la importancia de este componente? ¿Cómo lo enfrentan? Los aspectos más relevantes desde esta perspectiva son los saberes sobre el libro como objeto y el uso de estrategias de lectura material (derivadas de la materialidad del libro). Los primeros se concretan en la identificación de claves significativas en la página legal (con su inclusión en la secuencia narrativa), la alusión a las guardas y la atención a las cubiertas, dividida a su vez en el establecimiento de relación título-cubiertas-resto de la obra, importancia e inclusión en la secuencia narrativa. Las segundas, en procesos de verificación, autocontrol y relectura relacionados con la inclusión de las cubiertas en la secuencia narrativa.

Cuadro 2. Lectura material y estrategias de lectura implicadas. Contraste cuantitativo en porcentajes

\begin{tabular}{|c|c|c|c|c|c|c|}
\hline & \multicolumn{5}{|c|}{ SABERES SOBRE EL LIBRO COMO OBJETO } & \multirow{3}{*}{ 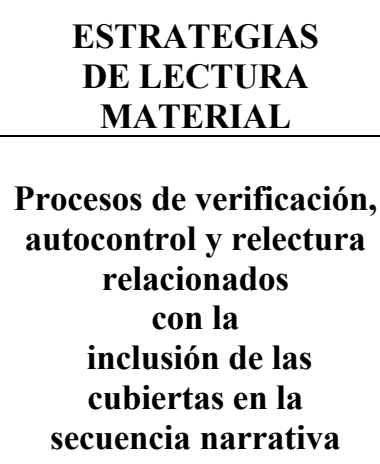 } \\
\hline & \multirow{2}{*}{$\begin{array}{l}\begin{array}{l}\text { Página le- } \\
\text { gal }\end{array} \\
\text { Inclusión } \\
\text { en la } \\
\text { secuencia } \\
\text { narrativa }\end{array}$} & \multirow{2}{*}{$\begin{array}{c}\text { Guardas } \\
\text { Alusión }\end{array}$} & \multicolumn{3}{|c|}{ Cubiertas } & \\
\hline & & & $\begin{array}{l}\text { Relación } \\
\text { título-cu- } \\
\text { biertas- } \\
\text { resto de la } \\
\text { obra }\end{array}$ & $\begin{array}{l}\text { Impor- } \\
\text { tancia }\end{array}$ & $\begin{array}{c}\text { Inclusión } \\
\text { en la secuen- } \\
\text { cia } \\
\text { narrativa }\end{array}$ & \\
\hline 䆓 & $0 \%$ & $0 \%$ & $0 \%$ & $0 \%$ & $0 \%$ & $0 \%$ \\
\hline : & $40.91 \%$ & $18.18 \%$ & $45.45 \%$ & $63.64 \%$ & $31.82 \%$ & $54.55 \%$ \\
\hline
\end{tabular}


Los comentarios iniciales develan la inexistencia de saberes sobre la materialidad del libro y el metalenguaje correspondiente y sobre las implicaciones de sentido de sus elementos, con los peritextos en primer término (Consejo, 2011; Lluch, 2009). A ello se suma una obvia falta de experiencia en la lectura de álbumes, que impide identificar la ruptura de las convenciones respecto de las funciones informativas y organizativas de cubiertas, guardas o página legal. El resultado es una lectura epidérmica e incompleta de Un día diferente para el señor Amos que establece un vínculo sesgado entre el álbum y un único destinatario a partir de la creencia de que las imágenes en las cubiertas presuponen un lector exclusivamente infantil. Los participantes aluden a la motivación que para los niños representan los personajes que aparecen en la contracubierta, y limitan la relación entre el conjunto de la obra y su título a la afirmación de que Amos es un hombre viejo y los animales son sus amigos, prescindiendo de una primera parte altamente significativa del peritexto ("un día diferente") y subvalorando su sentido:

El libro nos permite inferir, antes de abrirlo, que su contenido no es otra cosa que un tema infantil, las ilustraciones son un ejemplo de ello [...]. [...] el título por su falta de complejidad también hace referencia a la categoría infantil (E15).

La inconsciencia sobre la significación de la materialidad no permite implementar las estrategias interpretativas necesarias. Si bien la ruta de escritura de los estudiantes sugiere una lectura lineal de inicio a fin de la obra, desde la cubierta anterior a la posterior, no se incluyen los aportes objetuales a la historia, delatando la concepción errónea de la existencia de una frontera definida entre los niveles textual y peritextual.

En el comentario final, por el contrario, se percibe cómo el conocimiento sobre el libro como objeto revierte en la búsqueda del sentido de cada uno de sus componentes:

Es de recalcar que la historia comienza en la página legal y que no finaliza en la imagen donde todos duermen, ya que en la contracubierta hay una imagen que no está contenida en el libro y, relacionándola con lo dicho al final, se infiere que en realidad todo termina en la contracubierta, cuando los animales vuelven al zoológico (E14).

Los saberes sobre el funcionamiento del libro álbum y sobre cómo incide en la forma de leerlo se manifiestan en: 1) la interpretación de las imágenes de las cubiertas; 2) el establecimiento de relaciones semánticas entre las cubiertas, el título y la información contenida 
dentro del libro; 3 ) la relectura en busca de maneras de integrar a la secuencia narrativa aquello que queda materialmente fuera de ella y 4) el cuestionamiento sobre dónde se inicia y dónde termina la historia. Es decir, en estrategias para llenar vacíos y acceder a capas de significado más hondas, como se observa en este ejemplo: «La cubierta contiene el título y una ilustración que, ya leído el texto, nos complementa lo que sucedió cuando Amos se enfermó» (E15). Ello prueba la conciencia sobre la contribución de la materialidad del libro a la construcción literaria, lo cual genera una complejización de los procesos interpretativos al integrar los diversos modos de lectura que provoca el libro álbum, evidenciados en los comentarios con expresiones que denotan procesos de verificación, autocontrol y relectura.

\section{Lectura verbal, identificación de lugares comunes o singularidades e intertextualidad}

El texto estricto sigue siendo un elemento central del libro álbum. También lo son los lugares comunes, las singularidades y la intertextualidad, puesto que la LIJ, igual que toda literatura, dialoga permanentemente con la tradición cultural y literaria a la vez que busca la innovación y la originalidad. Los interrogantes planteados en este punto son: ¿Cómo consideran los participantes el código verbal y sus funciones? ¿Identifican e interpretan tópicos y singularidades? ¿Detectan relaciones con otros textos? Los aspectos más relevantes en este sentido son lectura verbal y función de recursos verbales particulares, identificación de lugares comunes y singularidades propuestos en la obra y referencias a la intertextualidad.

Cuadro 3. Lectura verbal, identificación de lugares comunes o singularidades e intertextualidad. Contraste cuantitativo en porcentajes

\begin{tabular}{|c|c|c|c|c|}
\hline & \multirow{2}{*}{$\begin{array}{l}\text { LECTURA VERBAL } \\
\text { Y FUNCIÓN DE } \\
\text { RECURSOS } \\
\text { VERBALES } \\
\text { PARTICULARES }\end{array}$} & \multicolumn{2}{|c|}{$\begin{array}{l}\text { IDENTIFICACIÓN } \\
\text { DE LUGARES COMUNES } \\
\text { O SINGULARIDADES }\end{array}$} & \multirow[t]{2}{*}{$\begin{array}{l}\text { INTERTEX- } \\
\text { TUALIDAD }\end{array}$} \\
\hline & & $\begin{array}{l}\text { Lugares } \\
\text { comunes }\end{array}$ & Singularidades & \\
\hline 窖 & $4.55 \%$ & $\begin{array}{c}\text { Lector infantil } \\
72.73 \%\end{array}$ & $0 \%$ & $13.64 \%$ \\
\hline
\end{tabular}

Bellaterra Journal of Teaching \& Learning Language \& Literature. 12.3 (Ago-Sept 2019) ISSN 2013-6196 


\begin{tabular}{|c|c|c|c|c|}
\hline \multirow{2}{*}{$22.73 \%$} & $\begin{array}{c}\text { Lector infantil } \\
\text { (Argumentación clara } \\
\text { y ampliación }\end{array}$ & $\begin{array}{c}\text { Complejidad } \\
\text { temática en la } \\
\text { del destinatario) }\end{array}$ & $\begin{array}{c}\text { Vínculos claros y } \\
\text { argumentados } \\
\text { obra }\end{array}$ & $22.73 \%$ \\
& & $13.64 \%$ & $22.73 \%$ & \\
\hline
\end{tabular}

En el comentario inicial la identificación y el análisis de los usos verbales resultan muy limitados. Los participantes no aluden a las marcas textuales asociadas con el tiempo, al uso de la letra mayúscula sostenida ni, en general, al valor narrativo y poético de las palabras. Al carecer de formación y de experiencia lectora suficientes respecto del libro álbum, asimilan la lectura al plano más superficial del texto, de modo que, una vez descifrado el código verbal en su nivel externo (estrictamente comunicativo y funcional), abandonan la posibilidad de leer entre líneas o de atribuir a los enunciados un sentido no literal. Cuando se refieren a lugares comunes, relacionan la obra con el lector infantil a causa de la presencia de imágenes (ya se ha visto), personajes animales y valores positivos, en una mirada simplista sobre la LIJ y las capacidades de los niños para leer textos diversos y complejos que neutraliza la opción de hallar nada singular en el relato:

La narración es cómoda, sencilla, muy colorida, emocional [...] tierna, divertida y muy posible dentro de esas historias y libros cargados de imágenes y de lindos mensajes adecuados para los niños (E4).

Las conexiones establecidas con otras obras dependen principalmente, a su vez, de la identificación de la amistad como temática de Un día diferente para el señor Amos. Sólo en dos casos se asocian el tema a un refrán y una de las imágenes a la fábula La liebre y la tortuga; pero sin interpretación alguna y en unos vínculos más referidos al valor educativo que a rasgos estéticos específicos.

En el comentario final, las alusiones a usos verbales particulares son todavía escasas, aunque hay participantes que remiten a ellos, lo hacen de manera más precisa y reconocen su valor narrativo, incluyendo estos usos en la articulación del sentido profundo de la obra. Así lo demuestra este fragmento:

El narrador es claro, "Cada mañana" "Todos los días" Amos sigue la misma rutina, casa, autobús, zoológico, casa [...] Cuando Amos enferma, sus amigos deciden ir a 
visitarlo y a cuidar de él, como él siempre, constantemente, “Todos los días” cuidaba de ellos (E14).

Respecto de la identificación de lugares comunes y singularidades, el lazo exclusivo entre la obra y el destinatario infantil desaparece porque se identifica el tratamiento literario del tema como singularidad de Un día diferente para el señor Amos y, por tanto, se contempla que un espectro más amplio de lectores disfrute del álbum. En palabras de un participante: «el lector no debe ser sólo infantil, puede ser de cualquier edad, por el valor estético, por los recursos artísticos de las ilustraciones y por el manejo narrativo» (E8). En cuanto a la intertextualidad, ahora los estudiantes comentan las dos referencias más evidentes dentro de la obra -una edición particular de La liebre y la tortuga (Esopo, 1982) y Buenas noches Gorila (Rathmann, 2001)- de manera argumentada y clara.

A pesar de las mejoras, parece claro que estos aspectos requerirían un trabajo más intenso y detenido, quizás porque no resultan tan espectaculares o novedosos como los anteriores.

\section{Dimensiones ético-filosófica y afectiva}

Los componentes ético-filosóficos y afectivos conforman dos de las dimensiones clave de los saberes y prácticas de una óptima educación literaria (Fittipaldi, 2013). El primero se vincula a temáticas y valores; el segundo, a la implicación personal del receptor. Dado que una buena formación lectora supone trascender la anécdota argumental y responder ideológica y afectivamente a las obras, los interrogantes planteados en este punto son: ¿Se aproximan los participantes a esta forma de lectura profunda y comprenden la complejidad de las temáticas y las posiciones desde las cuales se plantean? ¿Responden emocionalmente a ellas? Los aspectos más relevantes en este sentido son el tema y el valor pedagógico (asociado al lector infantil), más las emociones despertadas por la obra y la conexión con experiencias positivas de lectura o la conexión con la complejidad de la vida humana.

Cuadro 4. Dimensiones ético-filosófica y afectiva. Contraste cuantitativo en porcentajes

\begin{tabular}{|c|c|}
\hline DIMENSIÓN & DIMENSIÓN \\
EFECTIVA
\end{tabular}




\begin{tabular}{|c|c|c|c|c|}
\hline$\frac{1}{x}$ & $\begin{array}{c}\text { Tema: amistad [solida- } \\
\text { ridad-reciprocidad] } \\
63.64 \%\end{array}$ & $\begin{array}{c}\text { Valor pedagógico } \\
\text { (lector infantil) } \\
50 \%\end{array}$ & $\begin{array}{c}\text { Emociones despertadas } \\
\text { por la obra } \\
\text { [ternura, alegría, } \\
\text { tranquilidad] } \\
77.27 \%\end{array}$ & $\begin{array}{c}\text { Conexión } \\
\text { con experiencias } \\
\text { positivas de lectura } \\
\text { en la infancia } \\
45.45 \%\end{array}$ \\
\hline $\begin{array}{l}5 \\
0 \\
0\end{array}$ & $\begin{array}{l}\text { Tema: amistad } \\
\text { Identificación de sin- } \\
\text { gularidades } \\
59.10 \%\end{array}$ & $\begin{array}{c}\text { Valor pedagógico } \\
\text { (lector infantil) } \\
0 \% \\
\text { Cuestionamientos sobre } \\
\text { vejez, enfermedad, sole- } \\
\text { dad } \\
18.18 \%\end{array}$ & $\begin{array}{c}\text { Emociones despertadas } \\
\text { por la obra [ternura, ale- } \\
\text { gría, tristeza, humor] } \\
81.82 \%\end{array}$ & $\begin{array}{c}\text { Conexión con la } \\
\text { complejidad } \\
\text { de la vida humana } \\
81.82 \%\end{array}$ \\
\hline
\end{tabular}

En el comentario inicial, la identificación de la amistad como tema central y la remisión a las emociones provocadas por la lectura determinan las referencias a las dimensiones ético-filosófica y afectiva. Sin embargo, estas referencias son indirectas, se encuentran implícitas en los comentarios (no se expresa la conciencia de las múltiples facetas del hecho literario) y adolecen de superficialidad. En declaraciones como «Amos enferma y [...] los animales, sus amigos, lo visitan y lo cuidan como él lo hacía con ellos. Dejando así una buena enseñanza $[\ldots]$ para un público menor» (E8), se percibe que la posición favorable frente a la amistad por la reciprocidad y dedicación que supone se fundamenta en el carácter educativo atribuido a la obra. Los estudiantes, en lugar de profundizar en la relación íntima entre los personajes o en los conflictos existenciales del relato, reducen su interpretación a la transmisión de un mensaje moral a los lectores infantiles en un sentido estrictamente monológico. También remiten al placer que les genera la lectura, principalmente, en la medida en que evoca experiencias de la infancia: «me gustó muchísimo, recordé algunos momentos del pasado, cuando leíamos libros de este tipo. [...] La historia lógicamente enternece porque nos recrea un ambiente bastante infantil» (E22). Igual que en relación a los aspectos ya considerados, el comentario inicial viene determinado por la consideración reduccionista sobre Un día diferente para el señor Amos como obra infantil, y también por el desconocimiento de las cualidades estéticas de la LIJ, lo que conlleva la calificación inmediata del texto como fácil y sencillo sin ir más allá del plano argumental. 
Tras la formación docente, los participantes ahondan en la interpretación del álbum, comprenden su carácter dialógico, reflexionan más sobre los sentidos que moviliza y exponen, en consecuencia, una implicación lectora aumentada. Ello se manifiesta en una caracterización menos estereotipada del tema y en la admisión de las luces y las sombras de la existencia humana:

Pensar en un anciano de probablemente más de 70 años, que no habla más que con animales... Precisamente por esto último considero esta historia una narración triste y a la vez hermosa, que refleja cómo la soledad nos afecta (E9).

Como resultado de la experiencia estética derivada de la lectura, además, se trasciende la valoración simple de la enseñanza moral para considerar la obra en un marco mucho más amplio, esencialmente literario en sus componentes. Y significativamente, se descarta la exclusividad del destinatario infantil de la LIJ: «Es una historia que mezcla melancolía con humor, una historia que puede ir dirigida a todo tipo de lector» (E19).

\section{Construcción de la narración}

Conocer cuál es la historia que los participantes han comprendido e identificar cómo entienden e interpretan los elementos del discurso -la forma como se cuenta la historia- es especialmente importante para establecer sus saberes literarios y sus estrategias lectoras. Los interrogantes planteados en este punto son: ¿En qué elementos de la historia se fijan y cómo? ¿Identifican los elementos del discurso y les atribuyen significado? Los aspectos más relevantes en este sentido son: para los elementos de la historia, las referencias a la trama en términos de estructura o inicio-nudo-desenlace, la alusión explícita o la alusión implícita a los personajes y su clasificación, más la remisión al marco espaciotemporal-tiempo y espacio-; y para los elementos del discurso, las alusiones a la estructura narrativa, en su forma simple o mediante historias paralelas, y al narrador, ya sea a través de la alusión explícita o la clasificación. 
Cuadro 5. Construcción de la narración. Contraste cuantitativo en porcentajes

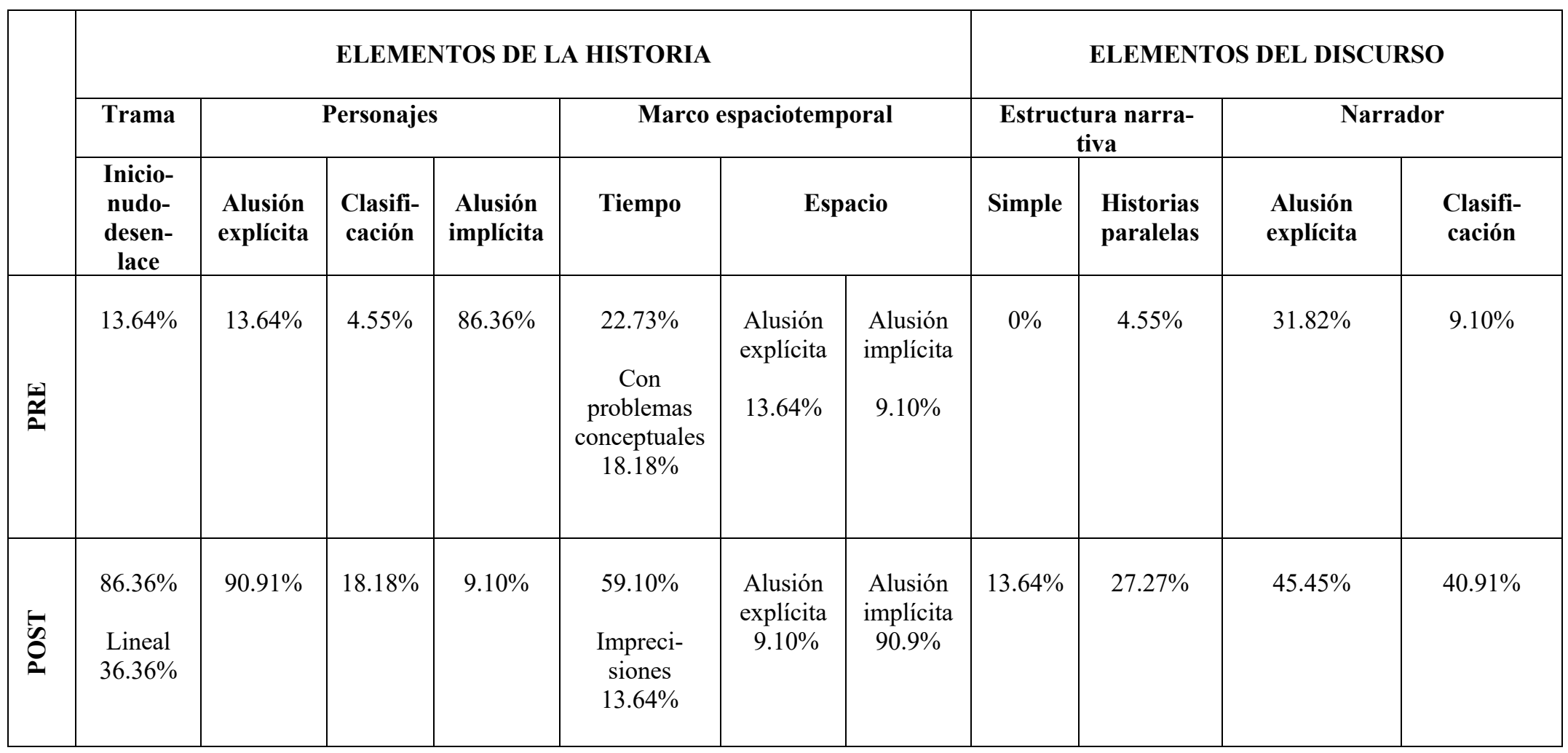


El comentario inicial muestra que la comprensión del texto se ve limitada por el desconocimiento de los elementos clave de la historia y del discurso. Si bien se percibe mayor densidad en las referencias al nivel de la historia, el uso de metalenguaje es escaso y la reconstrucción de la trama omite aspectos esenciales, reduciéndose a la paráfrasis argumental:

Nos narra la historia de un anciano que día a día va al zoológico a jugar con sus amigos animales y a hacerles compañía. [...] [O]curre en dos días, el primero nos describe lo que él hace por los animales y el otro lo que ellos hacen por él (E2).

Sólo unos cuantos participantes comentan mínimamente la estructura (inicio, nudo y desenlace). La mayoría se centra en los personajes, pero de manera implícita. Aunque se incide más en el narrador, buena parte de las explicaciones portan errores conceptuales como este: «La historia la narran a veces los animales, pero casi siempre el escritor» (E22).

En el comentario final, por el contrario, las alusiones a los componentes de la historia y del discurso se incrementan cuantitativa y cualitativamente. Esta progresión se percibe en el uso de metalenguaje, en la claridad comprensiva de las afirmaciones y en una reconstrucción y una interpretación más amplias y más complejas de la obra. Veamos dos muestras que contrastan con el fragmento de E2 arriba citado:

Nos cuenta una historia de manera lineal [...]; empieza hablándonos del señor Amos, que era muy madrugador, vivía solo y trabajaba en un zoológico, donde todos los días se tomaba tiempo para [...] sus amigos, los únicos que tenía, que eran animales. Pero un día Amos enferma y no puede ir a trabajar así que sus amigos preocupados deciden ir a visitarlo y a realizar las mismas actividades que Amos hacía con ellos en el zoológico. Finalmente, se acuestan juntos a dormir y al día siguiente los animales regresan al zoológico sin el señor Amos (E13).

La portada y la contracubierta juegan un papel esencial, porque la cubierta tiene el título y en él una imagen del día diferente [...], y en la contracubierta podemos ver que el final es abierto, ya que los animales regresaron al zoológico sin Amos (E8).

Los estudiantes, en esta oportunidad, integran -aunque hay que decir que no explícitamente- elementos no presentes antes de cursar la asignatura, como el tema de la soledad en la vejez o la trama, con su orden lineal y simetrías internas. E intensifican la consideración de otros que entonces abordaban de manera superficial o indirecta, como los peritextos. En algunos comentarios, sin embargo, se aprecian imprecisiones relacionadas con el tiempo y con las hipótesis sobre el fin de la historia, por lo que se debería reforzar el trabajo en esta línea. 


\section{Conclusión}

La experiencia lectora, fuente de aprendizajes a los cuales no es posible acceder por otras vías (Chambers, 2008), constituye un aspecto clave de la formación de los maestros de literatura. Y no únicamente por la extensión del corpus del que pueden hacer uso, sino por la adquisición y la consolidación de saberes literarios y de estrategias de comprensión e interpretación que enriquecen su propio bagaje y, por tanto, les convierten en mediadores más preparados. El estudio de caso llevado a cabo con la asignatura Didáctica de la literatura infantil y juvenil de la Universidad del Quindío, por un lado, evidencia las principales carencias formativas de los futuros docentes en torno al libro álbum como producto central de la LIJ actual y, por otro, demuestra algunos de los aportes que una preparación fundamentada en la experiencia lectora con este tipo de obras puede conllevar para que adquieran conciencia sobre la complejidad estética de la LIJ y sobre las opciones que ofrece a la educación literaria.

Antes del curso, los comentarios de los participantes sobre Un día diferente para el señor Amos exponen un desconocimiento generalizado tanto sobre el libro álbum y sus componentes visual, material y verbal como sobre los elementos literarios esenciales de la construcción narrativa en el marco de una visión reducida y simplista de la LIJ. Denotan, asimismo, una considerable debilidad de recursos comprensivos e interpretativos para enfrentar un texto literario, con prevalencia del carácter funcional (educativo) atribuido a la LIJ y exclusión de la implicación y el goce estético del lector. De ello surge el carácter inaplazable del trabajo, en la formación básica docente, sobre el sentido de las imágenes y la materialidad de los libros y sobre sus convenciones y posibles subversiones; un trabajo que sirva, globalmente y en especial, al despliegue y afianzamiento de estrategias para enfrentarse a los textos literarios.

Los comentarios posteriores a la asignatura prueban cómo en poco tiempo los futuros maestros pueden adquirir saberes fundamentales sobre los rasgos distintivos del libro álbum, sobre las piezas corales de un relato con intención artística y sobre la LIJ como producto cultural, con la ampliación y el enriquecimiento consiguientes de su concepción. Paralelamente, connotan un desarrollo remarcable de las habilidades de análisis literario, la incorporación de herramientas relevantes para la comprensión e interpretación ficcional y la adquisición de metalenguaje, aparte de incorporar el reconocimiento del placer estético del lector como posibilidad surgida de una lectura más profunda de la obra literaria y de la implicación promovida por dicha lectura en el proceso de recepción. 
Estos resultados confirman, en la línea de numerosas investigaciones recientes (Cerrillo y Yubero, 2007; Shaw, Dvorak \& Bates, 2007; Warmack, 2007; Deleuze, 2009; Cremin et al., 2011; Colomer, 2013; Morón \& Martínez, 2014; Munita, 2014; Real y Gil 2018), que urge mejorar la formación básica docente para que la educación literaria devenga más efectiva en las aulas. Es imprescindible incrementar y extender los conocimientos sobre la LIJ de los estudiantes de magisterio, sus habilidades analíticas frente a la literatura y su percepción de las virtudes de la LIJ. La asunción de esta tarea en la Universidad del Quindío ofrece una experiencia mejorable, acotada y poco representativa, en tanto caso concreto, pero óptima, reajustable y replicable, también como tal, al aportar un ejemplo de cómo los futuros maestros pueden convertirse en lectores más competentes y, en consecuencia, guiar mejor a sus alumnos cuando lleguen a las escuelas. Cabría esperar que los participantes de la investigación, más preparados para trabajar con los libros álbum de la Colección Semilla en sus clases mediante el curso Didáctica de la literatura infantil, se hayan transformado en mediadores capaces con los niños y niñas que ahora ya deben tener a su cargo. Comprobarlo tendría un interés incuestionable y abre vías investigativas de posible continuidad.

\section{Referencias}

Arizpe, E. y Styles, M. (2004). Lectura de imágenes. Los niños interpretan textos visuales. México: Fondo de Cultura Económica.

Belmiro, C. A. (2010). A multimodalidade na literatura infantil e a formação de professores leitores. Revista Brasileira de Linguística Aplicada, 10(2), 403-420. DOI: http://dx.doi.org/10.1590/S1984-63982010000200007

Bosch, E. (2007). Hacia una definición de álbum. AILIJ, Anuario de Investigación en Literatura Infantil y Juvenil, 11, 25-45.

Bosch, E. y Duran, T. (2009). Libros sin palabras: ¿Hay que aprender a leerlos? Elementos constitutivos de la imagen. En S. Yubero, J. A. Caride, y E. Larrañaga (coords.), Sociedad educadora, sociedad lectora: XXII Seminario interuniversitario de pedagogía social (pp. 317-326). Cuenca: Universidad de Castilla-La Mancha.

Cerrillo, P. (2016). El lector literario. México: Fondo de Cultura Económica.

Cerrillo, P. C.; Yubero, S. (2007). Qué leer y en qué momento. En P. Cerrillo y S. Yubero (coords.), La formación de mediadores para la promoción de la lectura (pp. 237-244). Cuenca: Universidad de Castilla-La Mancha. 
Chambers, A. (2008). Conversaciones. Escritos sobre la literatura y los niños. México: Fondo de Cultura Económica.

Chevallard, Y. (1991). La transposición didáctica. Buenos Aires: Aique.

Colomer, T. (2013). La literatura infantil: una minoría dentro de la literatura. En A forza das minorías. Actas del $32^{\circ}$ Congreso IBBY. Madrid: OEPLI

Colomer, T. (1999/2010). Introducción a la literatura infantil y juvenil. Madrid: Síntesis.

Colomer, T. (2005). Andar entre libros: la lectura literaria en la escuela. México: Fondo de Cultura Económica.

Colomer, T. (1991/1998). La formación del lector literario: Narrativa infantil y juvenil actual. Madrid: Fundación Germán Sánchez Ruipérez.

Consejo, E. (2011). Peritextos del siglo XXI. Las guardas en el discurso literario infantil. Ocnos, 7, 111-122.

Cremin, T., Bearne, E., Mottram, M., y Goodwin, P. (2011). Teachers as Readers in the 21st Century. En M. Styles y E. Arizpe (eds.), Acts of reading: Teachers, text and childhood (pp. 201-218). Stoke-on-Trent: Trentham Books.

De Souza Minayo, M. C. (2009). La artesanía de la investigación cualitativa. Buenos Aires: Lugar Editorial.

Deleuze, G. (2009). Futurs instituteurs et faibles lecteurs: réalité et/ou fatalité?. Enjeux, 74, 93100.

Díaz Armas, J. (2008). Lectura literaria y formación inicial: creencias del profesorado en formación sobre el texto y su lector. En A. Mendoza (coord.), Textos entre textos. Las conexiones textuales en la formación del lector (pp. 177-190). Barcelona: Horsori.

Doonan, J. (2005). El libro-álbum moderno. En B. Bellorín (ed.), El libro-álbum: invención y evolución de un género para niños (pp. 46-65). Caracas: Banco del Libro.

Dueñas, J; Tabernero, R; Calvo, V; y otros. (2013). La lectura literaria ante nuevos retos: canon y mediación en la trayectoria lectora de futuros profesores. Ocnos, 11, 21-43. Recuperado de http://www.revista.uclm.es/index.php/ocnos/article/view/390

Duran, T. (2009). Álbumes y otras lecturas. Barcelona: Octaedro.

Duran, T. (2008). Aprendiendo de los álbumes. Casa de leitura.org. ABZ da Leitura-Orientações Teóricas. Fundación Gulbenkian. Recuperado de http://www.casadaleitura.org/portalbeta/bo/documentos/ot_aprendiendo_de_los_albu mes_d.pdf 
Duran, T. (2007). El álbum: un modelo de la narratología postmoderna. Primeras Noticias de Literatura Infantil y Juvenil, 230, 31-38.

Duran, T. (coord.). (2000). ¡Hay que Ver!: Una aproximación al álbum ilustrado. Madrid: Fundación Germán Sánchez Ruipérez.

Esopo. (1982). Fábulas de Esopo: Barcelona: Salvatella S.A.

Fittipaldi, M. (2013). ¿Qué han de saber los niños sobre literatura? Conocimientos literarios y tipos de actuaciones que permiten progresar en la competencia literaria (Tesis doctoral). Departament de Didàctica de la Llengua, de la Literatura i de les Ciències Socials, Universitat Autònoma de Barcelona, Bellaterra.

Fittipaldi, M. y Colomer, T. (2014). Currículo literario y lectores escolares. Textos de Didáctica de la Lengua y la Literatura, 66, 17-24.

Gurdián, A. (2007). El paradigma cualitativo en la investigación socio-educativa. San José de Costa Rica: PrintCenter.

Hanan, F. (2017). Libro de resúmenes. $6^{\circ}$ Foro iberoamericano sobre literacidad y aprendizaje. Madrid: AELE Y ECOLE.

Hernández, R., Fernández, C., y Baptista, P. (2006). Metodología de la investigación. México: McGraw-Hill.

Lee, S. (2014). La trilogía del límite. Albolote: Barbara Fiore.

Lioni, L. (2005). Antes de las imágenes. En B. Bellorín (ed.), El libro-álbum: invención y evolución de un género para niños (pp. 150-155). Caracas: Banco del Libro.

Lluch, G. (2009). Textos y paratextos en los libros infantiles. Alicante: Biblioteca Virtual Miguel de Cervantes.

Martínez-Miguélez, M. (2010). Ciencia y arte en la metodología cualitativa. México: Trillas.

Massengill, D., Dvorak, M., y Bates, K. (2007). Promise and possibility - Hope for teacher education: Pre-service literacy instruction can have an impact. Reading Research and Instruction, 46 (3), 223-254. DOI: http://dx.doi.org/10.1080/19388070709558469

Mendoza, A. (1998). Tú lector. Aspectos de interacción texto - lector en el proceso de lectura. Barcelona: Octaedro.

Mercier, A. y Tourron-Bertrand, I. (2013). Formation des maîtres et littérature de jeunesse: un naufrage. BBF: Bulletin des Bibliothèques de France, 58 (2), 16-19.

Morón Olivares, E. y Martínez Agular, C. (2014). Las dificultades de los futuros maestros ante la LIJ: el ejemplo de Alfanhuí. Impossibilia, 8, 194-207. 
Munita, F. (2018). "Para mí todos eran cuentos": incidencia de la formación docente en las creencias y saberes sobre literatura infantil y juvenil”. Catalejos. Revista sobre Lectura, Formación de Lectores y Literatura para Niños, 3 (6), 102-125.

Munita, F. (2014). Reading habits of pre-service teachers / Trayectorias de lectura del profesorado en formación. Cultura \& Educación, 26 (3), 448-475.

Palomares Marín, M. (2015) Literatura infantil y universidad: un estudio descriptivo sobre la formación inicial del profesorado de Grado en Educación Primaria. Investigaciones sobre Lectura, 3, 44-66.

Rathmann, P. (2001). Buenas noches, Gorila. Caracas: Ekaré.

Real, N.; Gil, R. M. (2018). La formación básica de docentes de educación infantil en lengua escrita y literatura. El caso de la Universidad Autónoma de Barcelona - UAB. Educar em Revista, 34 (22), 131-150. Recuperado de: https://ddd.uab.cat/pub/artpub/2018/200223/PDF_publicat.pdf

Ruíz Dominguez, M. (2008). Rasgos del album metaficcional: El apestoso Hombre Queso y otros cuentos maravillosamente estúpidos” En A. Mendoza (coord.), Textos entre textos. Las conexiones textuales en la formación del lector (pp. 27-35). Barcelona: Horsori.

Shaw Massengill, D.; Dvorak, M. J.; Bates, K. (2007). Promise and possibility - Hope for teacher education: Pre-service literacy instruction can have an impact. Reading Research and Instruction, 46 (3), 223-254.

Silva-Díaz, M. C. (2014). Lectura de álbumes. Universidad Autónoma de Barcelona. Cataluña, España. Semana presencial del Master en Libros y Literatura infantil. Septiembre 29Octubre 3 de 2014.

Silva-Díaz, M. C. (2006). Algunas opciones y problemas metodológicos al observar la discusión literaria en el aula. En A. Camps (coord.), Diálogo e investigación en las aulas. Investigaciones en didáctica de la lengua (pp. 119-136). Barcelona: Graó.

Silva-Díaz, M. C. (2005). Libros que enseñan a leer: Álbumes metaficcionales y conocimiento literario (Tesis doctoral). Departament de Didàctica de la Llengua, de la Literatura i de les Ciències Socials, Universitat Autònoma de Barcelona, Bellaterra.

Silva-Díaz, M. C. (2001a). La formación de los maestros en literatura infantil: un estudio diagnóstico (primera parte). Cuatrogatos: Revista de Literatura Infantil, 5. Recuperado de https://www.cuatrogatos.org/detail-articulos.php?id=542 
Silva-Díaz, M. C. (2001b). La formación de los maestros en literatura infantil: un estudio diagnóstico (segunda parte). Cuatrogatos: Revista de Literatura Infantil, 6. Recuperado de https://www.cuatrogatos.org/detail-articulos.php?lang=es

Silva-Díaz, M. C. y Corchete, T. (2002). Ver y leer: historias a través de dos códigos. En T. Colomer (coord.), Siete llaves para valorar las historias infantiles (pp. 19-37). Madrid: Fundación Germán Sánchez Ruipérez.

Solé, I. (2001). Estrategias de lectura. Barcelona: ICE de la Universitat de Barcelona y Editorial Graó.

Stead, P. C. y E. E. Stead. (2012). Un día diferente para el señor Amos. Barcelona: Océano Travesía.

Turrión, C. (2012). La ambigüedad de significado en el álbum ilustrado. Bellaterra Journal of Teaching \& Learning Language \& Literature, 5 (1), 60-78.

Valencia Leguizamón, M. (2018). La Colección Semilla y la educación literaria para básica primaria en Colombia. Currículo, libro álbum y formación docente (Tesis doctoral). Departament de Didàctica de la Llengua, de la Literatura i de les Ciències Socials, Universitat Autònoma de Barcelona, Bellaterra.

Van der Linden, S. (2015). Álbum [es]. Barcelona-Caracas: Ekaré-Banco del Libro.

Van der Linden, S. (2006). Lire l'album. La Puy-en-Velay: l'Atelier du Possin Soluble.

Warmack, W. (2007). Elementary education Pre-Service Teachers' Attitudes Towards Reading (Tesis doctoral). Auburn University, Alabama, EUA.

\section{Notas}

${ }^{1}$ Ver Valencia (2018) para los contenidos del curso, diseñado en el marco de la tesis doctoral al origen de este artículo. Además de los libros infantiles y la formación básica docente, esta investigación integra también las políticas que regulan la educación literaria en Colombia para determinar las tendencias que deberían presidir la preparación de sus maestros desde la perspectiva de la didáctica de la literatura y del contexto de la realidad del país.

${ }^{2}$ Bosch (2007) ofrece un panorama creativo, inspirado en el lenguaje matemático, para representar las diversas posiciones de los estudiosos respecto a la presencia y la relación entre imágenes, texto y materialidad en el libro álbum.

${ }^{3}$ La Colección Semilla es una selección de obras que el estado colombiano organizó y distribuyó en los centros escolares del país como parte del Plan Nacional de Lectura y Escritura. Para su estudio detallado en relación con las políticas gubernamentales, ver Valencia (2018: 123-131 y 87-122).

${ }^{4}$ Para un análisis detenido de la obra, que excedería el espacio limitado de este artículo, ver Valencia (2018: 260276). 
Información sobre las autoras:

Mariana Valencia Leguizamón es doctora en Didáctica de la Lengua y la Literatura por la Universidad Autónoma de Barcelona con la tesis La Colección Semilla y la educación literaria para básica primaria en Colombia. Currículo, libro álbum y formación docente (2018). Es investigadora del grupo DiLeMa y profesora de Didáctica de la LIJ en la licenciatura en Literatura y Lengua Castellana de la Universidad del Quindío (Colombia).

E-mail: marianavalencia1@hotmail.com

Neus Real es máster en teoría literaria, doctora en Filología Catalana y miembro del grupo GRETEL del Departamento de Didáctica de la Lengua y la Literatura, y de las Ciencias Sociales de la Universidad Autónoma de Barcelona, donde trabaja como profesora agregada y coordina el Master de Biblioteca Escolar y Promoción de la Lectura. Actualmente investiga sobre literatura infantil y juvenil y educación literaria, especialmente en relación con la primera infancia, la formación básica docente y la ficción digital.

E-mail: neus.real@uab.cat

Para citar este artículo:

Valencia Leguizamón, M. y Real, N. (2019). Libro álbum y formación básica docente. Un estudio de caso en la Universidad del Quindío. Bellaterra Journal of Teaching \& Learning Language \& Literature, 12(3), 65-90. DOI: https://doi.org/10.5565/rev/jtl3.847 